\title{
ESTETICA, SUBJETIVIDAD Y CONOCIMIENTO
}

\section{Olimpia López Avendaño'}

RESUMEN: Este artículo trata de la tradicional dicotomía conocimiento objetivo-subjetivo. En él se analiza la posición de diferentes autores en búsqueda de los elementos que conducen al nacimiento de un nuevo paradigma, integrador, que supere la antinomia y permita visualizar al conocimiento pero sobre todo al individuo que lo produce, integralmente.

Abstracts: This article deals with the traditional dicotomia objective-subjective knowledge. In him position analyzes of different authors in search from elements that leads to the birth of a new paradigm, integrator, that surpasses the antinomy and allows to mainly visualize to the knowledge but the individual that produces it, integrally.

Palabras clave: FILOSOFIA/ TEORIAS/ OBJETIVIDAD/ SUBJETIVIDAD/ CONOCIMIENTO/ PENSAMIENTO/

\section{CONOCIMIENTO OBJETIVO Y SUBJETIVO}

Es frecuente escuchar que a fines de siglo $\mathrm{XX}$ los conceptos para interpretar el mundo aportados por la modernidad ya no son adecuados, dado que el conocimiento científico u objetivo, gran aporte de este periodo histórico, no da cuenta de los fenómenos y problemas cada vez más complejos con los que se enfrenta el individuo y la humanidad en la actualidad. De ahí que nuevas dimensiones y categorías parecen ser necesarias para explicar tanto el entorno social, cultural como natural. Por ello, la tradicional dicotomía objetividad-subjetividad para referirse a formas de conocimiento contrapuestos e irreductibles y peyorativamente denominados racional e irracional, requiere ser superada.

Algunos autores plantean que la filosofía ha sido responsable de esta radical separación, al contraponer pensamiento lógico e intuitivo, sentimiento e intelecto. Es en el siglo XVII cuando se instaura el culto a la razón y con los trabajos de Descartes se estable con mayor fuerza. Por ejemplo Najmanovich, (1995, p. 1), señala que :

\footnotetext{
1 Doctorado en Educación de la Universidad Estatal a Distancia. Doctorado en Filosofía en la Universidad de Costa Rica (egresada). Máster en Sociología de la Universidad de Costa Rica (1990). Licenciada en Administración Educativa de la Universidad de Costa Rica (1984). Bachiller en Educación de la Universidad de Costa Rica (1980). Profesora de Biología y Ciencias Naturales de la Universidad de Costa Rica (1970). Directora del Conseio Universitario de la Universidad de Costa Rica. e-mail: olopeza@cariari.ucr.ac.cl
} 
...pienso luego existo, es la frase que da el golpe de gracia a la dimensión subjetiva. La filosofía cartesiana instaura discursivamente un modo específico de relación del hombre como sujeto y el mundo como objeto que ya había comenzado a desarrollarse en el renacimiento. La noción de sujeto racional capaz de conocer la naturaleza como "lo otro de si" y elaborar una imagen o representación de la misma...

De este modo Descartes demarca el objeto de conocimiento y centra la certeza en el sujeto racional que se guía por el método. Sin embargo lo que interesa como objeto de conocimiento, en alguna medida, es lo medible o cuantificable.

El énfasis en lo cuantificable deriva de la concepción original de razón, que deriva del vocablo ratio, que quería decir cálculo o facultad de calcular y que posteriormente se amplia a la facultad de juzgar correctamente. Por ello se asignó como característica fundamental del conocimiento científico la posibilidad de expresar en forma cuantitativa relaciones entre las cosas (Kolakowski, 1969).

En relación con el culto a la razón Edgar Morin (1997), considera necesario hacer la distinción entre racionalidad y racionalización. En su perspectiva, el proceso vivido en la modernidad es ambivalente. Por un lado estimula el espíritu crítico, escéptico y autocrítico, por lo que la racionalidad busca y verifica la adecuación entre el discurso y el objeto del discurso. Por otra parte, la racionalización se encierra en su lógica, conduce al dogmatismo y desemboca en el establecimiento de la razón como diosa.

Aunado a lo anterior, cabe indicar que el presente muestra crisis paradigmáticas en el seno de las ciencias naturales, provocados por los más recientes aportes de la física, la genética y la neurobiología, que sugieren la necesidad de una revisión en las concepciones mantenidas en torno al fraccionamiento del conocimiento y sobre todo de las facultades cognoscitivas ser humano.

Dada la situación ya expuesta, el presente trabajo busca analizar, desde la estética como ciencia de la sensibilidad y la intuición, las posibilidades de una visión más integral de la forma de conocer humana. Para ello se parte de la posición estética kantiana dado que es a partir de su estructuración que se separan la sensibilidad del entendimiento. Se discuten la función de la imaginación, el símbolo y el sentimiento estético a partir de autores como Volumen 2, Número 2, Año 2002 
Abelardo Bonilla, Gilbert Durand, Edgar Morin, entre otros. Por otra parte, se plantean las interrelaciones que se dan entre las facultades humanas y los productos de su actividad, acumulados en las ciencias naturales y la producción estética. También, se plantean algunos postulados de la neurobiología como elementos que corroboran el error en que se incurre cuando se fracciona y jerarquiza las posibilidades del conocer y del sentir humano. Se finaliza con la presentación de algunos elementos que podrían constituir un paradigma alternativo al vigente.

\section{LA ESTETICA Y EL PENSAMIENTO OBJETIVO-SUBJETIVO}

De acuerdo con la etimología griega y según Abelardo Bonilla (1957), la estética es una ciencia de la sensibilidad, es decir una manera primaria y fundamental del conocimiento, previo al conocimiento conceptual o lógico. Es una manera del conocimiento que conduce a una representación especial del mundo en la conciencia. Desde su perspectiva, la estética no es filosofía del arte ni una ciencia de lo bello como algunos expositores lo han pretendido.

Existen diversas posiciones en torno a la importancia que se asigna a la intuición, la imaginación y la sensibilidad en el conocimiento. Por una parte, se le entiende como un medio que deforma la realidad por lo que sus productos son falsos. Por otra, como elemento de gran riqueza creativa, o bien como un factor que conduce a dos tipos de conocimiento irreductibles. Es con Kant con quien se inicia la separación entre conocimiento objetivo e intuitivo, de ahí que sea necesario aclarar algunos de sus postulados para intentar una reflexión en torno a este tema.

\subsection{La estética kantiana}

De acuerdo con Castillo, 1994, Kant define la estética trascendental como la ciencia de todos los principios a priori de la sensibilidad. Su estética se opone a la lógica trascendental que se refiere al entendimiento puro e implica la imaginación trascendental, concebida como un fenómeno de la intencionalidad de la conciencia. Esta facultad posibilita la creación, dado que mediante la percepción niega lo real e inventa lo irreal. Este proceso se lleva a cabo mediante la formación de imágenes y es válido tanto para el conocimiento objetivo como el intuitivo.

En Kant las imágenes pueden ser sensibles(empíricas) o puras (a priori y generales). Las imágenes sensibles se originan en la percepción y se localizan en un sistema de 
coordenadas espacio-temporales. Las imágenes sensibles se producen en la imaginación reproductora por percepción, pero requieren de las imágenes generales de la imaginación trascendental. Así, la percepción objetiva no es posible sin un esquema previo mediante el cual la imaginación establece la relación entre la representación del objeto y los conceptos como producto final. Sin embargo, la imaginación creadora también produce imágenes nuevas que no conducen a un concepto sino más bien al juicio estético. De este modo el juicio estético es un estado de conciencia del sujeto que no busca una finalidad racional, ni de utilidad, y es por tanto desinteresado. Su finalidad es el goce estético, la satisfacción. Si se juzga los objetos a partir de conceptos, la belleza desaparece. En este principio radica la diferencia entre conocimiento objetivo y subjetivo.

Desde este planteamiento se deduce que la imaginación y el esquema trascendental son punto de partida tanto para el conocimiento objetivo como intuitivo pero en determinado momento se producen dos formas de conocer opuestas. De esta forma Kant establece la dicotomía conocimiento objetivo-subjetivo, racionalidad e intuición, al establecer funciones diferentes de la imaginación, ya sea como creadora o como reproductora. Por otra parte, con su posición se establece un cambio cualitativo en el pensamiento filosófico, porque se asigna a la razón una función creadora, más que de reflejo de la realidad objetiva. Se pasa así de la razón contemplativa a la voluntad creadora, aspecto que determina el nacimiento de la era moderna en que predomina la razón como facultad creadora del mundo que conocemos (Serrano,1994).

\subsection{La imaginación en Gilbert Duránd}

Durand es un autor que reivindica la capacidad creadora de la imaginación al concebirla como una facultad esencial que se expresa en lo imaginario simbólico y como expresión de una psiquis única, en la que no existe ruptura entre lo racional y lo imaginario sino más bien una estrecha relación dialéctica.

Desde su perspectiva, la imaginación permite un mayor acercamiento a la felicidad que el pensamiento objetivo. Sin embargo, el símbolo fue desvalorizado, así como la imaginación como valor cultural, ante la preeminencia de la explicación científica cuantitativa del mundo que se expresa en el pensamiento filosófico de varios siglos. Aristóteles, Ockan, Descartes y el pensamiento positivista de varios siglos, condujeron a la secularización y materialización del mundo. 
Para Durand, la imaginación es una función equilibradora del ser humano en un nivel vital, psicosocial y antropológico. En un nivel vital, el proyecto imaginario facilita una mejora de su situación en el mundo porque permite al individuo visualizar alternativas ante la realidad concreta. En el nivel psicosocial, revitaliza la conciencia mediante el sentido de trascendencia que en última instancia contribuye a la salud mental. En el nivel antropológico, permite una revitalización planetaria mediante la constitución de un museo imaginario, que permite que los individuos se unan en torno a un reino de imágenes, en una especie de humanismo ecuménico y abierto. Así, la imaginación facilita la revitalización de utopías alternativas y de visiones de mundo contrapuestas y más ricas que la realidad misma.

En este marco, el símbolo es el elemento fundamental, porque remite a una realidad abstracta, invisible, concebible pero no representable. Esa realidad es la trascendencia, lo que está más allá de lo concreto. El símbolo constituye de ese modo un tipo de conocimiento, una gnosis que asegura la presencia de lo trascendente en lo personal. De esa forma se convierte en una afirmación de la libertad humana respecto de sus limitaciones. La imaginación y el símbolo en Durand son el punto de partida mediante el que reinvindica un tipo de conocimiento no objetivo y la valoración de la dimensión no racional de la humanidad (Güendell, 1998).

\subsection{La estética en Abelardo Bonilla}

Abelardo Bonilla (1957) concibe el conocimiento estético como una relación unitaria y recíproca de sujeto y objeto que se realiza mediante la intuición y se constituye en una estructura formal. En esta relación no se requiere el espacio, pero si del tiempo como un requisito fundamental que posibilita la intuición y se encuentra tanto en el sujeto como en el objeto. Desde su perspectiva esto es requisito fundamental para evitar caer en el error kantiano de separar ontológicamente la realidad exterior y el entendimiento interior.

Así, el conocimiento estético encuentra su punto de partida en las percepciones concebidas como formas proyectadas en el tiempo. Se trata de un tiempo fenomenológico y no cosmológico, que se entiende como una categoría del sentimiento que posibilita la proyección de la intencionalidad del sujeto, en forma libre, al eliminar las trabas de la razón. Así el conocimiento estético se sitúa en un plano autónomo diferente al de nuestra 
conciencia y al de la realidad exterior, capaz de crear su propio tiempo y de modelar cada estado del alma a su propio ritmo y siempre hacia un futuro emotivo.

Según su punto de vista hay dos caminos para explicar la percepción estética, uno es el del subjetivismo que asume la existencia de un sentido de lo bello a priori en los sujetos y otro, el del objetivismo que aduce el valor estético a los objetos. Ambas posiciones pueden objetarse. En contraposición plantea el ritmo como un apriori de la sensibilidad que permite ordenar y unificar en el tiempo los procesos de percepción. Para explicar el concepto utiliza la definición contemporánea de ritmo que proviene de la física. Así, el ritmo es una forma de energía universal que se encuentra integrada en el cuerpo y el espíritu. La conciencia recibe y refleja esta energía hacia la naturaleza exterior, con cuyo ritmo propio concuerda. El concepto de ritmo incluye una dimensión auditiva, visible y la acción. De esta forma, el sentimiento estético se puede manifestar en diferentes intensidades, y ante diferentes estímulos. Esto explicaría las diferencias y la variabilidad de percepciones estéticas, a partir de las diferencias de ritmo provenientes tanto del sujeto como del objeto, aspecto que no queda claro en el juicio estético kantiano.

Por otra parte, el autor plantea una relación estrecha entre razón y sentimiento. Reconoce que el pensamiento lógico influye en el conocimiento intuitivo o estético. Por ello en la percepción estética se puede establecer una lucha entre sentimiento y razón frente a la realidad del objeto que determina la forma en que se explora su apariencia. Ante una obra de arte, por ejemplo, puede entrar en pugna el sentimiento que provoca su contemplación o bien la crítica racional de carácter técnico. La explicación de este fenómeno las encuentra el autor en las imágenes y en la estructura de la percepción. La imagen se amplía y enriquece mediante la fantasía y el sentimiento, pero también se unifica por influencia de la razón que la devuelve al objeto concreto. Por tanto, la fantasía permite ir más allá de las cosas y crear imágenes en la percepción, enriqueciéndolas poéticamente con todos los aportes conscientes e inconscientes otorgando de esta forma, un ser a las cosas.

Este aspecto indica Bonilla, no sería aceptado por el racionalismo dado que es al pensamiento a quien se le ha adjudicado esta función. Sin embargo, considera que hasta ahora nadie ha explicado qué es el pensamiento, sino las funciones del representar y demostrar que le caracterizan y estas funciones no dicen nada sobre la esencia o estructura del pensar, que no puede concebirse puro sin los contenidos de la fantasía. Las formas Volumen 2, Número 2, Año 20026 
expresadas por la intuición poética no tiene una traducción lógica en la conciencia, de ahí que no puedan expresarse en formas lógicas del lenguaje, sino más bien en metáforas. En síntesis, verdad y belleza coinciden, porque la percepción estética también revela una verdad del ser, una verdad que se crea mediante la estructura de la percepción y que no debe ser juzgada como irracional. En realidad la verdad científica resulta más irracional porque debe ser previamente supuesta en hipótesis, las que posteriormente se atribuyen al ser.

De acuerdo con el autor tanto el conocimiento científico como el intuitivo parten de los datos primarios de las formas de la materia que constituye las estructuras fundamentales de la percepción. De este modo la estética es una ciencia de gran importancia indispensable a todas las actividades del conocimiento. Agrega además, que lo imaginable aunque no existe en la realidad puede expresarse formalmente en la pintura, literatura, música. Así que sobre la exterioridad objetiva se impone la subjetividad con su magia creadora.

\section{POSICIONES QUE APORTAN ELEMENTOS PARA LA BUSQUEDA DE UN NUEVO PARADIGMA, NO DICOTOMICO}

\subsection{Del desorden a la creación}

De acuerdo con Helman (1993) percibimos las cosas a través de las lentes que nos brindan las metáforas. Algunas de estas metáforas han tenido un valor colectivo paradigmático a lo largo de la historia. El reloj fue la metáfora dominante del siglo XVIII y la célula del XIX. En la actualidad, es el torbellino. El presente se caracteriza por un torbellino intelectual diferente al ordenamiento lógico que supone el concepto. La metáfora del torbellino refiere a un estado de imprevisión, carencia de direccionalidad, a un vacío ordenador. A esta situación le han llamado los investigadores atractores extraños. Estos sirven de motivación en la búsqueda de un cuerpo conceptual que permita entablar un orden, frente al aparente desorden. Un antecedente importante en esta búsqueda se encuentra en el método psicoanalítico de Freud, quien pretende mediante la libre asociación de ideas deconstruir el orden de la conciencia, para dar cabida a otro orden el del inconsciente. Se trataría de un caos que puede expresar un nuevo orden.

Sin embargo, hay otro tipo de caos, en el que los elementos no son susceptibles de orden ni regularidad conceptual, por tanto no puede esperarse el hallazgo de un orden oculto 
tras el desorden aparente. Estos hechos corresponden al campo de lo imprevisto, son elementos que no pueden ser imaginarizados y simbolizados, es más bien la irrupción de lo real, del acontecimiento no previsto, que se relaciona directamente con la creación. Este acontecimiento que irrumpe permite a los intelectos sensibles que traten de explicarlo, cuestionar los dispositivos tradicionales. El acontecimiento es así un atractor extraño

Desde otra perspectiva, el autor utiliza la metáfora del torbellino, para destacar el rol creativo del inconsciente. Parte de que lo real es el ojo del torbellino que actúa como el vacío en torno al que se organiza el movimiento. Lo real es lo excluido del circuito del pensamiento, de la imaginación y de la representación. Lo real trata de inscribirse en la subjetividad, e irrumpe en el interior de la cadena significante para deconstruirla, llevando un compacto de historia subjetiva no historizada, un recuerdo no recordado. Así, lo real emerge como acontecimiento y posibilita la creación en el inconsciente entendido como un desorden creativo. Así el caos es posibilidad de creación.

\subsection{Homo sapiens homo demens}

Edgar Morín (1997) es otro de los autores que se oponen a la separación radical entre pensamiento racional e irracional. Desde su perspectiva es necesario reconocer que en cualquier cultura existen dos tipos de lenguajes, el racional, empírico, técnico y el lenguaje simbólico, mítico, mágico. El lenguaje racional define, precisa y objetiva aquello de lo que habla. El simbólico busca traducir la verdad de la subjetividad mediante el uso de la analogía, y la metáfora. Así, cada lenguaje corresponde a un estado diferente de la conciencia. El primero, cubre gran parte de la vida cotidiana, en el que tratamos de razonar, el segundo es el estado poético. En las sociedades arcaicas se reconoce la importancia de ambos estados los que se conciben entremezclados, en cambio en la sociedad occidental se encuentran separados radicalmente, en dos tipos de pensamiento el científico y el poético, con una importancia significativa asignada al primero.

Plantea además, que en el romanticismo y el subrrealismo se dan dos intentos de rebelión ante tal dicotomía. Así, por ejemplo, Bretón, quiso asociar la fórmula revolucionaria política con "cambiar el mundo"con una forma de cambiar la vida y las actuaciones humanas en ella. Aunque esta manifestación subrrealista se asume en algunos casos, en forma extrema, tiene el valor de haber intentado el cambio. Este es urgente a fines de siglo cuando 
finalmente se comprendió que el ideal de progreso asumido desde el positivismo no es una ley de la historia. Por el contrario, hay que conquistarlo y redefinirlo constantemente. La conciencia de esta situación nos sitúa, según el autor, entre la noche y la bruma. Esta sensación de perdición, se profundiza con los aportes provenientes de la física y que ya han sido tratados por otros autores, expuestos con antelación.

Ante este estado de cosas el autor considera que hoy es posible un diálogo entre poesía y ciencia. La ciencia revela un universo fabulosamente poético, sin dejar de redescubrir los problemas filosóficos fundamentales. Hoy más que el reloj o la máquina de funcionamiento perfecto, vemos a un universo que surge del desorden, lo real que parecía tan sólido y evidente desaparece bruscamente, bajo la mirada de la microfísica, y bajo la mirada del cosmos, el tiempo y el espacio que parecían tan diferenciados se mezclan. En este marco, el fin de la poesía es llevarnos al estado poético. Morín (1997), cuestiona el modelo de dominio del mundo que se asumió en occidente, que se aleja de toda idea de sabiduría. Sin embargo, considera esperanzador que uno de los grandes logros de la conciencia contemporánea sea la idea de los límites y por ello hoy existe una toma de conciencia de la carencia, lo que revela la capacidad humana de tomar distancia respecto de sí misma. Desde su perspectiva, los problemas de occidente en torno al pensamiento encuentran explicación en una razón antropológica: el concepto de homo sapiens, donde sapiens es sinónimo de razón. Si se define homo únicamente como sapiens, se oculta su afectividad y se la disocia de la razón inteligente. Esta posición omite el importante dato que muestra como el desarrollo de la inteligencia en los mamíferos se correlaciona directamente con la afectividad (afecto, cuido de la prole etc). Inteligencia y afectividad han estado estrechamente correlacionadas en el proceso de evolución humana. A pesar de esto es necesario reconocer que la afectividad tiene un lado oscuro: cólera, rabia, stress. Sin embargo, ello no implica que deba desconocerse su existencia y sus posibilidades. De ahí que sea necesario aceptar la coexistencia de Homo sapiens y Homo demens. Es en esta contradicción aparente donde radica la invención, la imaginación, la creatividad, pero también la maldad.

Dados los yerros destacados, cree que en el presente lo que cabe es preguntarse si ser racional no es más bien el comprender los límites de la racionalidad y lo misterioso del mundo. Y,ante la sobrevaloración de la razón lógica, establecer el valor de la intuición, de la 
sabiduría, entendida como una autoética para sí y los demás, donde las ideas de venganza y otra similares sean rechazadas.

Así, la sabiduría radica en saber distanciarse de uno mismo, saber objetivarse, saber descubrirse y analizarse. También consiste en saber meditar y reflexionar a partir del reconocimiento de que la misma sabiduría lleva en sí misma una contradicción.

\subsection{Nietzsche el filósofo del cambio radical}

Alejandro Serrano se refiere a Nietzsche como el pensador más radical que jamás haya existido, porque acusa a la humanidad de haber permanecido en un grave error a partir de Sócrates, cuando se instaura la primacía del pensamiento lógico:

La pérdida de la fuerza y del vigor de toda una civilización ha sido, para Nietzsche consecuencia de un pensar estrictamente racional que supone y asume a través de los conceptos y de las categorías lógicas que es posible conocer la verdad, tocar racionalmente al ser, y crear una verdadera metafísica y una auténtica ontología (Serrano, 1994, p. 137)

Para Nietzsche, Sócrates disecó la fuente de la vida, por lo que es necesario volver a la poesía, al mito, a la música para lograr el desocultamiento de la verdad, en el sentido de la aletheia griega de develización del ser. De este modo se llegaría a un momento místico que permite tocar la verdad. De esta forma a la verdad no se llega por la razón, por eso la filosofía occidental ha colocado el velo de la razón que impide tener acceso a ella, como una especie de película que impide la relación sujeto-objeto. Así que la verdad ontológica es un fenómeno místico que se encuentra más cerca del éxtasis que de la razón. En congruencia con lo anterior, Nietzsche considera que el mito constituye la esencia de la sabiduría:

Disfrutar el placer y asumir el dolor, asumir las fuerzas de la naturaleza y el instinto, las fuerzas inconscientes e institntivas más que racionales y conscientes, la intuición, la manifestación y la revelación, integrarse a las fuerzas universales de la naturaleza y tener consciencia de que el indiviuo sólo es parte de esa corriente universal, es en el fondo el imperativo dionisíaco que plantea la filosofía de Niezstche (Serrano, 1994, p.138). 
En congruencia con el planteamiento freudiano, para Niezstche, la forma espontánea del ser está reprimida en el sector más profundo del subconsciente y los siglos de represión impuestos por la razón impiden su manifestación. Serrano (1994), destaca la congruencia de Nietzsche manifiesto en su forma de escribir filosofía a partir de un lenguaje poético de gran belleza, con el uso de alegorías y metáforas: "el genio de Nietzsche es capaz de hacer filosofía a partir de imágenes y de construir una racionalidad a partir de mensajes poéticos" (p.141).

\section{LA BUSQUEDA DE UNA SINTESIS RAZON-SUBJETIVIDAD A INICIOS DEL SIGLO XXI}

Dada la diversidad de elementos expuestos a lo largo del documento, el presente muestra la necesidad urgente de una síntesis que devuelva al humano su unidad. En búsqueda de elementos que ayuden en esta búsqueda Najmanovich (1995), intenta una relación entre el desarrollo de las ciencias naturales, sobre todo la física, con las metáforas que se generan y la dinámica que se entabla en otros ámbitos del pensamiento.

Así como la filosofía kantiana coincide con el apogeo del paradigma newtoniano cuyos principios fundamentales son: unidad, universalidad y reversibilidad. y se constituyen en los ejes centrales de la visión de mundo del siglo XVIII, en el siglo XIX aparecen las flechas del tiempo y del cambio, con los conceptos de evolución en biología y de entropía en la física termodinámica. Así el concepto de entropía conduce a atender el desorden y la desestructuración. Por su parte, el concepto de evolución remite a la complejidad. Estas vinculaciones conducen a entender que la diferencia y el caos no son solo fuente de error, sino también de novedad y de creación.

Al estudiar sistemas abiertos los físicos encontraron que en condiciones alejadas de equilibrio se producían fenómenos insospechados, no previstos por la física clásica, tales como interacción de sus moléculas, comunicación, autoorganización, creación de nuevas estructuras, que evolucionan hacia una nueva estructura que denominaron disipativa. De este modo, la física plantea una nueva relación sujeto-objeto y se cuestiona los postulados básicos de causalidad, determinismo, objetividad, universalidad. 
Najmanovich (1995), considera que otra consecuencia de estos hallazgos es la necesidad de interdisciplinariedad a que conducen. Así por ejemplo en filosofía, se arriba a la comprensión de que la realidad no puede entenderse como un dato objetivo y que el sujeto se disuelve como entidad metafísica y aparece constituido por las múltiples relaciones de saber- poder que forman la sociedad contemporánea: “el sujeto-sujetado".

Así, la separación entre filosofía y ciencia deja de tener sentido. Más bien parece ser necesario el diálogo entre ellas. De ahí la necesidad de un espacio transdisciplinario donde sea posible pensar la ciencia como práctica humana y cultural en un mundo caracterizado por la inventiva.

En la misma línea de pensamiento, Miguel Martínez (1993) plantea la necesidad de un nuevo paradigma, que parece emerger de la interrelación entre las disciplinas, incluida la filosofía, cuya característica fundamental es la coherencia lógica, sistémica y ecológica de un todo integrado de saberes, que fueron fragmentados históricamente. Este paradigma constituiría una teoría global de la racionalidad científica.

De acuerdo con el autor, la ciencia no puede resolver a cabalidad muchos problemas de la vida humana, ni justificar contundentemente las bases o supuestos en que se apoya, debido a limitaciones metodológicas. Para ello requeriría en primer lugar autoobjetivarse, convertirse en su propio objeto de estudio y en segundo lugar, de una metaciencia. Sin embargo, el reconocimiento de esta situación es cuestionado por quienes asumen una posición objetivista, por temor a que se debiliten las bases firmes del conocimiento científico e irrumpa la irracionalidad.

Por otra parte, reconoce que la ciencia tradicional ha contribuido en gran medida al desarrollo de la humanidad, pero al querer llevar el método científico a todos los campos, deformaron la poesía y la prosa. Por ello, hace suya la frase de Bertrand Russell "la ciencia, como persecución de la verdad, será igual, pero no superior al arte".

Martínez intenta justificar su reflexión sobre la integralidad del conocimiento, mediante los descubrimientos de la neurociencia. Así expone que el cerebro estructural y funcionalmente permite la unidad e interrelación entre los saberes humanos, llámense objetivos o subjetivos. En esta línea de argumentación aporta datos interesantes que Volumen 2, Número 2, Año 200212 
conducen a revalorar la dimensión intuitiva y no consciente del individuo. Así por ejemplo, señala que la velocidad de información del sistema nervioso no consciente supera la imaginación humana (1 a 10 millones de bits lo que equivale a más de 300 páginas del lenguaje de un libro normal). La experiencia consciente o inconsciente, así como el conocimiento hereditario inconsciente se registra en el aparato neuronal y es utilizado cuando las condiciones lo requieren. Por otra parte indica que el cerebro tiene áreas llamadas comprometidas que sirven para realizar funciones específicas y otras no comprometidas. Estas últimas no tienen una ubicación espacial completa y su función no está definida genéticamente. En los animales las áreas comprometidas son la mayoría mientras que en el ser humano la mayor parte del cerebro no está comprometida, más bien está disponible para un futuro no programado.

Otro aspecto que destaca el autor es la vinculación entre las emociones y el funcionamiento del cerebro. Así cuando la mente está libre de mecanismos defensivos dispone de la multitud de datos del cerebro, a veces inconscientemente y genera conclusiones que se le presentan como intuiciones, en una especie de sabiduría del organismo. Estos juicios pueden ser más sabios que los de carácter estrictamente racional porque en ellos se acepta lo que aparentemente es incoherente.

La interrelación es de tal naturaleza que hoy se avanza en las teorías que postulan que los sistemas emotivo y cognitivo constituyen una sola estructura emocional-cognitiva. Ello debido a la red de estructuras que interrelacionan las entradas sensoriales, el sistema límbico y los lóbulos cerebrales.

Dado lo anterior las posibilidades de creación descansan más en el nivel inconsciente y la intuición, que permite su manifestación. Eso explica porqué las intuiciones que han llevado a grandes descubrimientos científicos ocurren en momentos de reposo posteriores a intensos fracasos en la búsqueda. Por eso la intuición no es una simple conjetura, sino más bien una visión intelectual de una relación que no ocurre por vía de razonamiento sino que simplemente arrastra hacia la verdad, mediante fuertes sentimientos de convicción.

\section{A MANERA DE SINTESIS}

El conocimiento acumulado hasta la fecha por la humanidad permite reconocer y hechar por tierra definitivamente toda división y separación entre las formas del conocer 
humano. De esta forma se puede emitir juicio en torno a la concepción kantiana para quien conocer es sintetizar, ligar lo múltiple en el concepto, separándose radicalmente de la intuición originaria. Así, aunque reconoce la imaginación como punto de partida de todo conocimiento, las versiones reproductoras y creadoras de la misma llevan a dos tipos de conocimiento irreductibles, con el agravante de la sobrevaloración del conocimiento de tipo lógico.

Los conocimientos de la neurociencia son coincidentes con las reflexiones de autores como Gilbert Durand en el sentido de plantear la existencia de una psiquis única que integra dialécticamente lo racional y lo imaginario. Sin embargo, aunque el planteamiento de Durand es sugestivo, cuando intenta reinvindicar lo imaginario-simbólico, el pensamiento racional continúa siendo preponderante en la vida del sujeto. De esta forma su pensamiento no trasciende la dicotomía que critica.

Resulta fecundo el concepto de ritmo de Abelardo Bonilla, como elemento explicativo de la sensibilidad estética, así como su planteamiento sobre la imposibilidad de concebir el pensar sin los contenidos de la fantasía. Desde su perspectiva, inclusive en la formulación de hipótesis, fundamento del pensamiento científico se encuentran elementos de irracionalidad, dado que su formulación no es coincidente con la realidad más bien contienen una gran dosis de imaginación. Sin embargo, a pesar de la acertada aseveración anterior, su planteamiento conduce a visualizar el sentimiento estético más en la dimensión artística que en la de las ciencias en general. El concepto de ritmo, por ejemplo aunque se inspira en un concepto de la física se aplica a las diversas sensaciones ante lo artístico. No logra el autor vincular el ritmo con las diversas percepciones del individuo ante la realidad, lo que podría hacer la diferencia, entre el ritmo que se establece entre Newton y la manzana que cae y el de otros individuos frente el mismo hecho. No hay duda que en estas situaciones se presentan ritmos diferentes ante el mismo fenómeno y que en el momento en que se da el descubrimiento de Newton convergen la intuición, el sentimiento, la razón y el goce estético.

Helman (1995), por su parte, intenta un rico diálogo entre paradigmas provenientes de ciencias de diferente naturaleza. A partir de este diálogo reinvindica la subjetividad manifiesta en el aparente desorden del inconsciente frente a la consciencia, como factor que permite crear nuevas formas de comprender la realidad del sujeto. Así el caos, al igual que Volumen 2, Número 2, Año 200214 
en la naturaleza permite al individuo trascender la realidad y construir nuevas formas para su desarrollo. El inconsciente, concebido tradicionalmente como el sitio de lo oculto lo prohibido, especie de basurero de la mente, deviene en espacio que posibilita trascender lo cotidiano, para generar nuevas relaciones de significado.

Morín y Martínez coinciden en el diálogo existente entre poesía y ciencia, entre Homo sapiens y Homo demens, entre inteligencia y sensibilidad. De la obra del primero se desprende un paradigma unificador como el planteado por Martínez, aunque no se refiera a la estructura biológica que posibilita la unidad del ser humano.

Por otra parte, la pasión de Nietzsche en contra de la primacía del pensamiento lógico es válida. Sin embargo, su radical oposición es valiosa como denuncia, más no como factor que conduzca a la superación de la perspectiva atomizante del ser humano. Su planteamiento contribuye más bien a mantenerla pero esta vez suplantando la razón por la imaginación.

A estas alturas de la reflexión es importante destacar la importancia de los resultados a que condujo el pensamiento científico en los últimos siglos. Sin embargo, se trata no de la ciencia entendida como dogma, la racionalización como diría Morin, sino de la razón como elemento de búsqueda de la verdad a partir de la verificación. En este proceso así entendido, aunque no se reconozca explícitamente, subyacen grandes dosis de subjetividad, intuición e imaginación creadora. La ciencia que crea es una ciencia que se vive y experimenta como goce estético, de lo contrario no hubiese sido posible el descubrimiento teórico en ámbitos tan "irreales" como la microfísica y el universo.

De ahí que los grandes aportes científicos sea producto de momentos de creación donde no se podrían señalar los límites del pensar y del sentir. Y, aunque no estuviera en capacidad de comprenderlo, dado el grado de desarrollo científico el ser humano siempre ha producido conocimiento, como un ser integral y unitario valiéndose tanto de sus posibilidades objetivas, como subjetivas, aunque algunos productos de su accionar creativo no hayan recibido la legitimidad social. En este momento, el desarrollo del conocimiento es tal, que si es posible reconocerlo. 
A pesar de los errores que condujeron a la dicotomía, algunos de los productos del trabajo científico "objetivo", permiten hoy, cuestionar tal posición y propiciar el nacimiento de una nueva perspectiva paradigmática, aspecto de gran importancia para la educación. La ciencia y el conocimiento producido por la humanidad no ha sido estéril, dado que el ser humano, a pesar de las ideas filosóficas de corte cartesiano, en la práctica, hizo uso de todas sus posibilidades en el proceso creador, aunque no estuviese en capacidad de reconocerlo.

Hoy al objetivarse, tomar distancia y analizar con visión histórica su accionar, la humanidad está en posibilidad de perfeccionar el conocimiento históricamente acumulado sobre la visión de sí mismo, y por tanto puede entenderse y explicarse mejor como sujeto producto y productor de una cultura.

En este marco es que tienen cabida posiciones pedagógicas integrales en las que el sentimiento y la intuición marginados históricamente como elementos válidos de los procesos educativos, puedan desempeñar el papel que les corresponde en la adquisición del conocimiento y en las posibilidades de crear e innovar del ser humano. Estos elementos a la vez permiten reconocer la pertinencia de nuevas teorías sobre la inteligencia en las que se abandona el énfasis en el pensamiento lógico-matemático, sobre valorado hasta la fecha, para visualizar otras manifestaciones o formas de la inteligencia. Son ejemplos de ellas la teoría de las inteligencias múltiples y la de la inteligencia emocional. No hay duda que estos elementos legitiman asignaturas, metodologías, enfoques de enseñanza-aprendizaje que ocupaban un lugar marginal en la currícula de los centros educativos. Algunas de estas asignaturas son la música, las artes plásticas, la religión, la educación física, por citar algunas.

Desde otro punto de vista, el reconocimiento de las emociones como elemento válido en la enseñanza-aprendizaje conduce a visualizar la motivación y el sentimiento que genera, con nueva mirada. Esta posición paradigmática que se vislumbra podría revolucionar la educación en todos sus niveles, aún más que la incorporación de las nuevas tecnologías como herramienta de trabajo en el aula y fuera de ella, en la que tanto se enfatiza actualmente. Finalmente se está en capacidad de ofrecer una educación formal integral, concepto que ha estado presente en los discursos educativos modernos, pero ausente de la realidad cotidiana del centro educativo. 
Por otra parte, la reinvindicación de la imaginación y los imaginarios como elementos centrales de las utopías, se convierte en un instrumento válido para enfrentar los retos de una sociedad cada vez más compleja y como elemento central en la conservación de la integridad mental del individuo. Este es uno de los mayores retos de la educación de inicios de siglo, en un mundo donde un contexto turbulento que aporta información abundante y variada, dificulta una toma de decisiones en la que se tenga grados de certeza sobre los criterios de verdad que prevalecen en la misma y sobre su validez ética, de forma que puedan incorporarse en los sistemas de valores y la moral que guía el accionar de los individuos y de la colectividad.

\section{BIBLIOGRAFIA}

Bonilla, Abelardo. (1957) Conocimiento verdad y belleza. San Salvador: Departamento Editorial Ministerio de Cultura,.

Güendel, Herman. La imaginación simbólica en Gilbert Durand. Inédito.

Helman, Jorge. (1995) La subjetividad entre la escritura y el subconsciente. En Acheronta, Número 1, Agosto.

Kant, Emmanuel. En Castillo, Roberto. (1994) La imaginación trascendental en Kant, hacia una estética del espacio. En Revista de Filosofía Universidad de Costa Rica, XXXII (78-79),189-194,.

Kolakowski, Leszek. (1993) Tratado sobre la mortalidad de la razón. Caracas: Monte Avila Editores, 1969. En Martínez, Miguel Angel. El paradigma emergente. Barcelona: Editorial Gedisa S.A.

Morin, Edgar. (1997) Amor, poesía y sabiduría. Montevideo: Ediciones Trilce.

Najmanovich, Denise. (1995) La metamorfosis de la ciencia. En Acheronta, Número 1.

Serrano, Alejandro. (1994) El doble rostro de la posmodernidad. San José: Editorial Nuevo Amanecer. 